\title{
Nicho de Aprendizagem Matemática: uma experiência de ensinar e aprender matemática em convivência
}

\author{
Graziela Rossetto Giron ${ }^{1}$ \\ Eliana Maria do Sacramento Soares ${ }^{2}$
}

\section{Resumo}

Apresentamos resultados de uma pesquisa que objetivou desencadear a emergência de dinâmicas de cocriação de atividades que pudessem favorecer a aprendizagem matemática, à luz de alguns conceitos da teoria da Biologia do Conhecer. Por meio desta "experiência de convivência", envolvendo a professora e os alunos do 8o ano do Ensino Fundamental de uma escola municipal da Serra Gaúcha, foram vivenciadas atividades relacionadas à exploração do Minecraft. O contexto no qual se desenvolveu essa experiência educativa foi denominado Nicho de Aprendizagem Matemática. Os resultados revelam pistas, possibilidades que indicam que quando os processos de ensinar e aprender estão apoiados em dinâmicas que favorecem a cocriação pedagógica, a aprendizagem acontece naturalmente e torna-se prazerosa.

Palavras-chave: Aprendizagem Matemática; Biologia do Conhecer; Nicho de Aprendizagem; Convivência.

\section{Mathematical Learning Niche: an experience of teaching and learning mathematics in coexistence}

\section{Abstract}

We present the results of a research that aimed to trigger the emergence by co-creation dynamics of activities that could favor mathematical learning, in the light of some theory concepts of the Biology of Knowing. Through this "coexistence experience", involving the teacher and students from elementary school 8th grade at a municipal school in Serra Gaúcha, activities related to the exploration of Minecraft were experienced. The context in which this educational experience was developed was called Mathematical Learning Niche. The results reveal clues, possibilities indicating that when the processes of teaching and learning are supported by dynamics that favor pedagogical co-creation, learning happens naturally and becomes pleasurable.

Keywords: Mathematical Learning; Biology of Knowing; Learning Niche; Coexistence.

\section{Introdução}

Apresentamos os resultados de uma pesquisa expressa numa tese de doutorado ${ }^{3}$ que indica pistas/processualidades relacionadas aos processos de ensinar e aprender matemática, à luz da Biologia do Conhecer. Essas possibilidades pedagógicas emergiram da convivência entre a professora de matemática (e também pesquisadora) e seus oito alunos que, no período de

\footnotetext{
${ }^{1}$ Universidade de Caxias do Sul (UCS), Caxias do Sul, e-mail: ggrosseto@gmail.com

${ }^{2}$ Universidade de Caxias do Sul (UCS), Caxias do Sul, e-mail: emsoares@ucs.br

${ }^{3}$ A tese intitulada: Movimentos de ensinar e aprender matemática em convivência foi desenvolvida por Graziela Rossetto Giron, no PPGedu da Universidade de Caxias do Sul, no período de 2016 a 2019, sob orientação da Profa . Dra. Eliana Maria do Sacramento Soares.
} 
setembro a dezembro de 2017, frequentavam o 8o ano do Ensino Fundamental, numa escola municipal da região Nordeste do Rio Grande do Sul. Durante essa experiência, permeada pelo fluir do/no conviver, professora e alunos cocriaram diferentes atividades relacionadas à exploração do Minecraft, um software em forma de jogo que foi escolhido de forma coletiva, objetivando desencadear a aprendizagem de alguns conceitos matemáticos relacionados à geometria.

A Biologia do Conhecer é uma teoria biológica para os seres vivos desenvolvida, inicialmente, em laboratórios de pesquisa por Humberto Maturana e Francisco Varela, que tem como pressuposto básico a premissa de que o conhecer é um fenômeno biológico que emerge na convivência. Segundo Soares e Rech (2009, p.147), "esta abordagem teórica ocupa-se da caracterização dos seres vivos a partir da dinâmica dos processos que os constituem e não com base no rol de suas propriedades ou de seus constituintes."

A partir dessa teoria Maturana e Varela (1997) questionam a existência do conhecimento objetivo de mundo, abordando, cientificamente, questões que até então, estavam reservadas à filosofia e psicologia. Está pautada na visão sistêmica e propõe-se, prioritariamente, investigar a atividade cognitiva dos seres vivos por meio de suas raízes biológicas e historicamente situadas, num ambiente de interações sociais dinâmicas. "Trata-se de uma epistemologia que traz definitivamente, para o âmbito da ciência, o observador, o sujeito do conhecimento" (VASCONCELLOS, 2005, p. 06).

A opção por utilizar a Biologia do Conhecer como referencial teórico deveu-se, principalmente, ao fato de que a mesma oferece elementos conceituais que podem auxiliar a repensar e a propor alternativas de transformação para os processos de ensinar e aprender. Trata-se do giro ontológico da modernidade (PELLANDA, 2009), isto é, do surgimento de uma nova tendência histórica e cultural que propõe uma forma ampliada de ver/perceber o mundo.

Na perspectiva desta teoria, a aprendizagem não é algo pré-determinado ou prédefinido; consiste num movimento histórico, dinâmico, efêmero e recursivo ${ }^{4}$ de desenvolvimento dos seres vivos, ao longo da sua constituição (MATURANA; VARELA, 1997). A

\footnotetext{
4 A recursividade acontece quando um procedimento é aplicado sobre o resultado da operação anterior, estabelecendo-se, dessa forma, uma relação de interdependência entre as partes que estão interagindo.
}

Periódico Horizontes - USF - Itatiba, SP - Brasil - e020053 
Biologia do Conhecer sustenta que a aprendizagem aflora de um processo dinâmico de transformação do ser vivo em congruência com o meio, situação que favorece o rompimento da visão convencional e "assistencialista" do ensino, onde, para aprender, alguém precisa ensinar.

O desejo de repensar o ensino da matemática, a partir dessa ótica, tem relação com o fato de que essa área do conhecimento faz parte do cotidiano da maioria das pessoas, estando presente tanto nas experiências mais simples da vida (como: contar, comparar, mensurar, classificar, seriar e operar sobre quantidades), quanto nas tarefas mais complexas (aquelas relacionadas com a robótica, a informática, as engenharias, dentre outras).

Embora o conhecimento matemático seja fruto de um processo, o ensino da matemática está, geralmente, baseado em informações sobre resultados formalizados (definições, procedimentos de cálculos, regras e fórmulas), através das quais são propostas resoluções para problemas e atividades muitas vezes desvinculadas dos significados conceituais que originam a aplicação das práticas propostas.

O aluno, à luz dessa concepção de ensino, tem dificuldades em desenvolver o raciocínio matemático; na maioria das vezes, aprende a manipular símbolos, a fazer cálculos e a executar algoritmos sem refletir sobre esses procedimentos e sobre como esses conceitos podem estar relacionados com os fenômenos da realidade. Esse é o ensino que queremos transformar, pois destacar apenas regras e leis matemáticas já estabelecidas, sem considerar seus fundamentos, não promove o pensamento lógico, criativo e intuitivo, como também pouco colabora para o desenvolvimento das aptidões intelectuais matemáticas.

Nesse sentido, partimos do pressuposto de que é necessário redimensionar a prática do ensino da matemática, a fim de que sua aprendizagem possa ter potencial para ampliar o raciocínio lógico-dedutivo, a interpretação, a comparação, a generalização, a organização, o equacionamento de problemas, dentre outras condutas relevantes que estão vinculadas ao conhecimento matemático.

Objetivando desenvolver uma pesquisa que pudesse indicar esse caminho, foi escolhida como delineamento metodológico a cartografia, "uma prática investigativa que, ao invés de buscar um resultado ou conclusão, procura acompanhar o processo" (COSTA, 2014, p.70), deixando vir à tona os sentimentos, pensamentos, intuições, percepções e outras situações 
inusitadas que fazem parte do contexto investigativo.

Tendo em vista que a cartografia possibilita perceber a realidade em movimento e contemplando diferentes aspectos, pontuamos que a ação investigativa não ocorreu apenas como uma representação da realidade, como um objeto estático a ser interpretado e com "verdades ocultas" para serem desveladas; constituiu-se, outrossim, numa possibilidade criativa de mostrar elementos a serem vivenciados, recriados e redimensionados durante o processo da própria pesquisa.

Para cartografar essa experiência educativa foram utilizados diferentes recursos, entre eles: gravações em áudio e vídeo, autonarrativas dos alunos (a fim de explicitar o que estavam sentindo, percebendo, apreendendo/ou não na convivência), bem como narrativas feitas pela professora num "Diário de Bordo", que ajudaram a clarificar suas ideias a respeito das dinâmicas vividas.

O domínio de ação (MATURANA, 2001a), isto é, o contexto no qual se desenvolveu a experiência de convivência que serviu de objeto de estudo para a pesquisa desenvolvida, foi denominado Nicho de Aprendizagem Matemática. O conceito de nicho foi utilizado para simbolizar um ambiente educativo que teve como inspiração as ideias apresentadas por Maturana e Dávila (2015), que olham para o sujeito imerso em seu contexto; defendem que o nicho emerge em congruência com o próprio organismo que o habita, num processo contínuo de vir-a-ser.

Neste caso, o nicho foi o cenário educativo formado pela professora e seus oito alunos, em interação com os conhecimentos matemáticos, com o Minecraft, com os sentimentos, os questionamentos, as dúvidas, as curiosidades, as ansiedades, os desejos, os saberes, as expectativas e as dinâmicas pedagógicas que afloravam do conviver.

Essa convivência entre a professora e os alunos foi permeada pela exploração do Minecraft, o que possibilitou a cocriação de diferentes atividades que se revelaram desencadeadoras da aprendizagem matemática, mais especificamente dos conceitos de geometria, as quais serão melhor descritas a seguir. Os alunos e seus pais foram informados sobre a pesquisa e assinaram um termo de consentimento esclarecido; o projeto de pesquisa foi aprovado pelo Comitê de Ética. 


\section{Movimentos iniciais da experiência de convivência}

A ideia de acoplamento ${ }^{5}$ (MATURANA; VARELA, 1997), relacionada ao conviver em legitimidade, com acolhimento às diferentes formas de entender os processos de ensinar e aprender matemática, permeou toda a experiência educativa desenvolvida no Nicho de Aprendizagem Matemática. Um conviver que pressupôs estar junto com o outro compartilhando saberes e experiências de vida desde uma postura interna que não julga, mas que acolhe o jeito de ser do outro, validando e respeitando seus saberes e emoções, postura que legitimou e fortaleceu as relações do/no grupo.

Os primeiros "movimentos" do conviver nesse contexto foram iniciados quando a professora realizou uma conversa com a turma acerca do que gostariam de aprender. Foi um momento descontraído e despretensioso em que todos puderam externar quais assuntos despertavam sua curiosidade, mesmo que não estivessem diretamente relacionados com os conteúdos de matemática estabelecidos no programa curricular.

Como resultado desse diálogo ficou definido que os conceitos de geometria seriam estudados tendo como foco a exploração do Minecraft, um software em formato de jogo que permite ao aluno realizar operações matemáticas, explorando e simulando diferentes situações que emergem das jogadas. Objetivando que todos pudessem conhecer as possibilidades de manuseio do Minecraft, bem como operar com seus recursos de maneira ampla, foram organizados grupos de estudo nos quais os alunos puderam explorar e interagir, entre si e com o software.

De acordo com Murta, Valadares e Moraes Filho (2015), a possibilidade de definir e construir a própria experiência de aprendizagem favorece a autonomia, a criticidade, a inventividade e o desenvolvimento do raciocínio lógico-dedutivo, aspectos significativos para a construção do conhecimento. No entanto, um dos desafios vividos durante a experiência de aprender e ensinar matemática por meio do Minecraft foi relacionar as ações propostas pelo software com os conceitos matemáticos. Por diversas vezes os alunos argumentaram que não

\footnotetext{
${ }^{5}$ Para esses autores, acoplamento é o mecanismo subjacente à transformação do ser e, portanto, desencadeador da aprendizagem.
}

Periódico Horizontes - USF - Itatiba, SP - Brasil - e020053 
sabiam explicitar como haviam raciocinado, por terem "feito os cálculos de cabeça" (M)

$\mathrm{O}$ fato deles apresentarem dificuldades em perceber e/ou expressar o seu pensamento, levou a professora a concluir que eles não tinham clareza sobre quais conceitos matemáticos estavam relacionados com a exploração do Minecraft. Visando a facilitar essa compreensão, sugeriu que os alunos criassem suas próprias dinâmicas para explicitar o raciocínio que estavam utilizando, dando legitimidade aos registros pessoais e as formas de comunicar que emergiam da convivência.

Posteriormente, através de conversações ${ }^{7}$ nas quais a professora buscou sustentar de modo consciente uma atitude interna de respeito e escuta atenta, foi possível fazer aproximações entre a linguagem formal matemática e o registro preliminar dos alunos, no intuito de qualificar a compreensão e a comunicação dos conceitos matemáticos que estavam sendo mobilizados pelo grupo.

Isso é coerente com as ideias de Devlin (2004), quando o mesmo destaca que os processos de ensinar e aprender matemática ocorrem de forma mais profícua quando: privilegiam a reflexão e a troca de ideias; os conteúdos são explorados de diferentes formas e perspectivas, e é oportunizado que o aluno reflita sobre eles e sobre as relações que podem ser estabelecidas com a realidade vivida; o aluno atribui sentido ao que está estudando.

\section{Seguindo no movimento de convivência}

Várias dinâmicas pedagógicas, além da exploração do Minecraft, emergiram da experiência de convivência desenvolvida no Nicho de Aprendizagem Matemática, oportunizando uma maior compreensão sobre os conceitos matemáticos relacionados à geometria. Entre elas, destacamos: a exploração do Tangram ${ }^{8}$, a construção de alguns sólidos geométricos, a confecção da planta baixa (tanto no plano real quanto no Minecraft) de uma

\footnotetext{
${ }^{6}$ Os alunos serão identificados pela letra inicial do nome. Quando houver dois nomes iniciando com a mesma letra, utilizaremos a vogal imediatamente posterior.

${ }^{7}$ Conversação é um termo utilizado por Maturana e Varela (1997) para simbolizar o fluir da linguagem com emoção. Não se trata de uma simples conversa que ocorre entre duas ou mais pessoas, pois, segundo esses teóricos, a linguagem está diretamente ligada às relações humanas, que, por sua vez, estão intrinsicamente vinculadas à emoção.

${ }^{8}$ Trata-se de um antigo jogo chinês, que permite a formação de figuras por meio de sete objetos geométricos (um quadrado, um paralelogramo e cinco triângulos).
} 
casa fictícia, bem como a construção da maquete desta casa.

A exploração do Tangram foi iniciada no Laboratório de Informática Educativa (LIE) da escola, intencionando conhecer a história que deu origem ao jogo, o que contribuiu para que os alunos pudessem contextualizar o que estavam estudando. Posteriormente, o grupo foi convidado a explorar o Tangram, visando a conhecer as peças que o constituem, assim como decifrar possibilidades de combinação entre elas.

Itzcovich (2012) enfatiza que para compreender as propriedades de um objeto geométrico não é suficiente apresentar os nomes, as particularidades e os elementos que o caracterizam. É interessante que o(a) professor(a) ofereça situações-problema que favoreçam o estabelecimento de relações entre o objeto, a geometria e os saberes cotidianos do aluno; oportunize o desenvolvimento das aptidões em saber comunicar (oral e de forma escrita) as peculiaridades/particularidades das figuras geométricas em estudo; incentive a exploração de objetos físicos (bi e tridimensionais), bem como proponha a resolução de desafios envolvendo a geometria, auxiliando, assim, na ampliação do pensamento geométrico e no desenvolvimento do raciocínio lógico-dedutivo do aluno.

Após o reconhecimento das peças do Tangram e das propriedades geométricas presentes nas mesmas, a turma foi convidada a explorar esse jogo montando figuras de acordo com a sua imaginação e, depois, de forma orientada. O interesse dos alunos em realizar essa atividade levou a professora a desafiá-los novamente; propôs que montassem quadrados utilizando 2, 3, 4, 6 e 7 peças do Tangram e, posteriormente, desenhassem essas figuras numa folha de ofício, objetivando, assim, ampliar a percepção dos alunos acerca do raciocínio geométrico.

Essa prática foi bem desafiadora para o grupo, pois, além de solicitar a utilização do pensamento espacial, requisitou o estabelecimento de relações de proporcionalidade e de simetria, a fim de que pudessem fazer o desenho dos quadrados. Segundo Itzcovich (2012), a aprendizagem dos conceitos geométricos implica num constante ir e vir entre o objeto e a sua representação. Logo, saber quais são os elementos que constituem uma figura geométrica, assim como retratá-la com fidelidade, estabelecendo relações de proporcionalidade entre o contexto real e sua ilustração, resultam em uma experiência significativa para compreender os conceitos que caracterizam o pensamento geométrico. 
Após várias coordenações de coordenações de ações ${ }^{9}$ (MATURANA et al., 2009), aqui simbolizadas pelos movimentos de montar os quadrados, medir as peças, desenhar no papel, refletir sobre as produções e criar outras possibilidades de resolução da tarefa, os alunos descobriram que ficava mais fácil se utilizassem como medida padrão um dos quadrados já existente no Tangram, desenhando, no seu interior, as outras figuras geométricas necessárias para formar a ilustração desejada.

Maturana (2001a) chama esse movimento em que cada operação realizada (levando-se em conta o que se aprendeu em cada uma delas) é ponto de partida para as que seguem, de recursividade. Cada vez que os alunos tinham a oportunidade de conversar e refletir acerca do que estavam fazendo, bem como experimentar diferentes formas de realizar a atividade sugerida, agregavam-se outros elementos ao seu pensamento inicial, desencadeando um processo de complexificação ${ }^{10}$ que acabou transformando sua forma de ver/pensar os conceitos geométricos.

Ao serem convidados a explicitar o raciocínio matemático utilizado na montagem das figuras, bem como manifestar as facilidades/dificuldades vivenciadas durante a exploração do Tangram, alguns alunos se pronunciaram dizendo:

O jogo do Tangram me ajudou a entender que diversas formas com tamanhos e formatos diferentes são capazes de formar diversos seres e objetos (N).

Pude entender que, com formas diferentes, podemos formar figuras e aprender diversas retas e ângulos (J).

Eu tive que aprender a resolver problemas, porque não sabia como fazer para montar aqueles quadrados (I).

Diante dos depoimentos acima, inferimos que a exploração do Tangram desencadeou várias transformações/aprendizagens ${ }^{11}$ no grupo, entre as quais, aprender a resolver

\footnotetext{
${ }^{9}$ Consiste num movimento recursivo que ocorre no e com o ser vivo, em congruência com o meio, de onde emergem novas condutas, novos elementos a cada ação realizada.

${ }^{10}$ Complexificação é um termo utilizado por Maturana et al. (2009) para simbolizar transformações que ocorrem na estrutura interna de um ser vivo, mediante movimentos de tomada de consciência sobre si mesmo e/ou sobre as relações que estabelece com o meio.

${ }^{11}$ Tendo como inspiração os pressupostos teóricos da Biologia do Conhecer, optamos por estabelecer uma relação de similaridade entre os conceitos de transformação e aprendizagem. A partir dessa teoria, quando um indivíduo se
}

Periódico Horizontes - USF - Itatiba, SP - Brasil - e020053 
problemas. Diniz (2001) reforça que quando o(a) professor(a) incentiva os alunos a buscarem diferentes soluções para determinada tarefa, ampliam-se as possibilidades de conhecer como eles percebem ou entendem os conceitos matemáticos.

Corroborando, Ponte, Brocardo e Oliveira (2006) sinalizam que trabalhar com a resolução de problemas no ensino da matemática desencadeia um processo investigativo e reflexivo que favorece o desenvolvimento do raciocínio lógico no aluno. Acrescentam que, para além de resolver problemas, é possível fazer outras descobertas e percepções que podem se revelar tão ou mais importantes que a própria solução do exercício. "A investigação matemática, como atividade de ensino e aprendizagem, ajuda a trazer para a sala de aula o espírito da atividade matemática genuína, constituindo, por isso, uma poderosa metáfora educativa" (PONTE; BROCARDO; OLIVEIRA, 2006, p.23).

Ainda inspirados pelos movimentos de cocriação que afloravam da convivência, professora e alunos decidiram, coletivamente, montar alguns sólidos geométricos. O primeiro deles foi um tetraedro (utilizando canudinhos plásticos), o segundo foi um cubo (usando varetas de madeira), entre outros que foram construídos em cartolina. Além de permitir um maior entendimento acerca dos conceitos geométricos, essa dinâmica despertou a curiosidade dos alunos em conhecerem o nome dos poliedros, entenderem a relação entre o nome e a quantidade de lados desses sólidos, bem como compreenderem a forma de calcular o perímetro e a área dos mesmos. Para isso realizaram buscas no Laboratório de Informática Educativa (LIE) da escola.

À medida que os alunos construíam os sólidos geométricos; pesquisavam, conversavam e refletiam sobre as propriedades/elementos da geometria presentes nesses poliedros; realizavam cálculos de área e perímetro dos mesmos, foram complexificando sua forma de entender os conceitos geométricos, o que desencadeou transformações estruturais que levaram a diferentes aprendizagens relacionadas ao tema.

Ao observar mais atentamente essa experiência de convivência, concluímos que o pensamento geométrico se desenvolve com mais facilidade quando é oportunizado aos alunos a vivência de situações em que possam pesquisar, observar, explorar, desenhar e construir

complexifica, isto é, amplia a consciência sobre si mesmo e/ou sobre o mundo, são desencadeados movimentos de transformação em sua estrutura, levando a aprendizagem.

Periódico Horizontes - USF - Itatiba, SP - Brasil - e020053 
figuras geométricas, num movimento recursivo que considere a interação entre os conceitos matemáticos formais e os saberes do grupo. Essas dinâmicas também contribuem para o estabelecimento de relações entre os sólidos geométricos e sua nomenclatura, bem como a compreensão de fórmulas, teoremas e algoritmos utilizados na resolução de situaçõesproblema vinculados à geometria, dando sentido à aprendizagem matemática.

\section{Ampliando a compreensão dos conceitos geométricos}

A elaboração da planta baixa e da maquete de uma casa fictícia, idealizada em duplas, tanto no plano real quanto no virtual (por meio do Minecraft), foram atividades que afloraram do desejo manifestado pelo grupo em ampliar seus conhecimentos acerca da geometria. Para tanto, foi necessário que realizassem estudos prévios visando a compreender melhor o que é uma planta baixa e qual sua finalidade, como também diferenciar planta baixa, de planta frontal e do desenho em perspectiva.

Na sequência, depois de uma conversa sobre diferentes formas de confeccionar uma planta baixa, as duplas iniciaram as atividades; desenharam a planta baixa de uma casa fictícia num papel quadriculado, pois entendiam que isso poderia facilitar a representação das suas medidas, bem como o estabelecimento de relações com os cubos existentes no Minecraft. Para tal, foi criada uma legenda que contribuiu para especificar a correlação entre as medidas da maquete, da planta baixa e do desenho que seria realizado no Minecraft.

Em coerência com as ideias de convivência que perpassam esse estudo, inferimos que os alunos refletiram e vivenciaram a construção da planta baixa de acordo com as suas concepções, de forma que as operações que emergiam da convivência e das conversações no grupo, funcionaram como mola propulsora para ampliar a maneira dos alunos pensarem/entenderem a matemática. Melhor dizendo, ao mesmo tempo em que a professora e seus alunos conviviam, também iam se transformando, ou seja, aprendendo.

Nas palavras de Maturana (1993, p.32),

[...] a tarefa do educador é criar um espaço de convivência para qual se convida o outro, de modo que o outro esteja disposto a conviver conosco, por um certo tempo, espontaneamente. E nessa convivência, ambos, educador e aprendiz, irão transformar-se de maneira congruente.

Periódico Horizontes - USF - Itatiba, SP - Brasil - e020053 
Nesse sentido, depreendemos que, à luz da Biologia do Conhecer, o papel do(a) professor(a) é criar e validar, na convivência com os alunos, um modo específico de viver e de conhecer, mediante o respeito e acolhimento mútuo, uma vez que "a aceitação do outro como um legítimo outro não é um sentimento, é um modo de atuar. Se atuo de modo que um observador possa dizer que o aceito, a aceitação se dá; mas se não o faço, a aceitação não se dá" (MATURANA, 2002, p.66).

As interações mútuas e recorrentes com o meio são operações que sustentam o acoplamento estrutural ${ }^{12}$. Este, por sua vez, é fortalecido pelas conversações, onde os sujeitos estão juntos numa história de interações que tem como requisito básico serem construtivas e acolhedoras, legítimas, ou seja, sem negação e julgamento. Uma conduta que aceita o outro na convivência é caracterizada por relações que denotam respeito e aceitação do outro em seu espaço de existência, em sua dignidade e legitimidade (MATURANA, 2001b).

À medida que os alunos desenhavam a planta baixa e faziam os cálculos de área e perímetro relativos à mesma, conversando, explorando e refletindo sobre as propriedades/elementos da geometria ali presentes, também iam ampliando a sua forma de ver e de pensar esses conceitos. Ao fazerem isso, modificavam sua percepção acerca do assunto, potencializando uma transformação em sua estrutura biológica e desencadeando a aprendizagem. Logo, o aprender ocorre a todo o momento e de maneira mútua, "como uma transformação estrutural contingente com uma história no conviver [...]" (MATURANA, 2002, p.32). Ao serem convidados a falar sobre quais foram as facilidades/dificuldades e descobertas que tiveram ao desenhar a planta baixa no Minecraft, um dos alunos manifestou-se dizendo:

Criar a planta baixa ajudou muito a construir a casa no Minecraft, pois as medidas estavam todas na planta baixa e era só ter as mesmas medidas no jogo que ficava muito fácil de construí-la, além de que, no jogo, pude economizar um monte $(\mathrm{sic})$ de material. Concluí que, para construir uma casa na vida real ou no Minecraft, é preciso criar uma planta baixa para ter uma noção de quanto material iremos utilizar (F).

\footnotetext{
12 Maturana e Varela (1997) denominam de acoplamento estrutural o processo de estar em congruência com o meio, em sintonia, o que poderá desencadear complexificações na estrutura interna do indivíduo, possibilitando transformações/aprendizagens.
}

Periódico Horizontes - USF - Itatiba, SP - Brasil - e020053 
Com base nas considerações explicitadas acima, conjecturamos que a confecção da casa no Minecraft, a partir do desenho da planta baixa, facilitou a visualização, a percepção e o entendimento dos alunos sobre vários conceitos matemáticos relacionados aos cálculos de área e perímetro. Nesse sentido, os recursos tecnológicos - no caso, o Minecraft - são uma alternativa pedagógica que tem potencial para auxiliar a visualização e a exploração de alguns conceitos geométricos, além de favorecer a resolução de situações-problema que emergem da sua exploração.

Contudo, um aspecto importante a ser considerado pelo(a) professor(a) quando utiliza recursos tecnológicos objetivando favorecer a aprendizagem matemática, é considerar se o mesmo tem potencial de perturbar o aluno a ponto de desencadear reflexões que auxiliem nos processos de ensinar e aprender. Segundo Balacheff (2000), o foco da utilização da tecnologia na educação não deve ser, apenas, a realização de uma determinada tarefa ou a ação mediatizada pelo dispositivo tecnológico, mas sim, propiciar que o aluno ressignifique o raciocínio utilizado na resolução da atividade proposta, a partir da tecnologia. A isso o autor denomina de transposição informática.

A transposição computacional ou transposição informática foi proposta pelo estudioso francês em Educação Matemática Nicolas Balacheff, com o intuito de ressaltar as modificações do saber a ser ensinado a partir dos requisitos básicos da representação simbólica da computação (FERNANDES, 2007). Balacheff (2000) defende que quando o aluno faz uso da tecnologia para aprender, diferentes processos cognitivos são desenvolvidos, pois o computador executa algumas tarefas práticas (como: cálculos, representação de figuras, montagem de gráficos etc.) que ajudam na construção de estruturas mentais, contribuindo, assim, com a ampliação do raciocínio matemático.

A confeç̧ão da maquete da casa, proveniente da construção da planta baixa e do desenho feito no Minecraft, simbolizou a etapa final da experiência de convivência que o grupo se propôs a vivenciar no Nicho de Aprendizagem Matemática. Todos os alunos ficaram muito entusiasmados com a possibilidade de construírem essa maquete, atividade que foi permeada por diferentes desafios que, aos poucos, puderam ser sanados por meio da conversação, da escuta atenta, da convivência e do desejo de aprender juntos.

Diante disso, inferimos que quando professor(a) e aluno se percebem como parceiros 
de aprendizagem, ou seja, quando têm a oportunidade de estarem juntos, refletindo e conversando sobre os conceitos matemáticos (sem julgamentos ou pré-conceitos); se abrindo para diferentes formas de perceber e de raciocinar sobre a matemática, ampliam-se as possibilidades de aprendizagem. A sala de aula torna-se um local de busca, de pesquisa, de descobertas e de troca de ideias pautada no "respeito e aceitação ao outro como legítimo outro em convivência" (MATURANA, 2002, p.68), o que dá sentido aos processos de ensinar e aprender matemática.

\section{Movimentos avaliativos percebidos no Nicho de Aprendizagem Matemática}

O processo de avaliação esteve inserido em toda a experiência de convivência desenvolvida no Nicho de Aprendizagem Matemática, uma vez que emergiu das atividades cocriadas pelo grupo. Logo, não foi necessário conceber um instrumento ou um momento específico para que os alunos pudessem ser avaliados; isso foi acontecendo no processo vivido.

No entanto, ficou combinado que ao final dessa vivência educativa o grupo deveria ter condições de: expressar, verbalmente e por escrito (através de desenhos, esquemas ou linguagem escrita) o raciocínio matemático inerente às situações-problema que emergiam da convivência; associar a linguagem formal da matemática às diferentes maneiras de simbolizar os conceitos matemáticos que afloravam do conviver; registrar as compreensões desenvolvidas a partir das tarefas vividas/realizadas, aspirando revelar uma mudança de comportamento/conduta na forma de ver a matemática e de lidar com as questões do cotidiano.

Para auxiliar na percepção dessas transformações/aprendizagens, cada aluno confeccionou um portfólio ou dossiê que reunia suas reflexões acerca das atividades vivenciadas no Nicho de Aprendizagem Matemática. Após cada tarefa realizada, o grupo era convidado a narrar (oralmente e na forma de texto, desenho ou esquema) o que estava entendendo/sentindo/percebendo acerca dos conceitos matemáticos desenvolvidos, dinâmica que possibilitou aos alunos tornarem-se observadores de si mesmos (MATURANA, 2001a).

De acordo com a Biologia do Conhecer, esse movimento de pensar sobre o pensar está relacionado com dinâmicas recursivas de olhar para si; tem relação com coordenações de 
coordenações de ações (MATURANA et al., 2009) e com movimentos autopoiéticos ${ }^{13}$, na medida em que o indivíduo está movimentando suas próprias estruturas para pensar e repensar no que faz, refletindo e reorganizando sua ação a cada novo movimento. Em outras palavras, implica em olhar para si mesmo e, ao fazer isso, complexificar-se, no sentido de perceber os processos vividos de uma forma mais ampla, redimensionando-os, quando necessário.

Maturana e Rezepka (2000) apontam que, com raras exceções, todos podem aprender, pois, apesar de não se tratar de um fenômeno simplório, a aprendizagem é algo que acontece o tempo todo. Aí reside a importância do(a) professor(a) desenvolver a sensibilidade para perceber o que o aluno está manifestando através da fala e dos registros escritos, bem como o que não está sendo dito por ele, pois a linguagem corporal e o silêncio também revelam o quanto o aluno sabe, ou não, sobre determinado assunto. Quando o(a) professor(a) não está atento(a) para isso, pode deixar passar uma oportunidade significativa de perceber o que está sendo compreendido e o que ainda precisa ser redimensionado nos processos de ensinar e aprender.

O enunciado: "Viver é conhecer. Conhecer é viver", proferido por Maturana e Varela (1997), reforça a ideia de que a aprendizagem tem relação direta com a ação do indivíduo no mundo, numa dinâmica de vir-a-ser. Logo, todo ato cognitivo empreende uma ação efetiva que permite ao indivíduo continuar sua existência num mundo que ele mesmo fez surgir, enquanto se mobiliza para conhecê-lo. Dito de outra forma, não existe conhecimento sem experiência, como também não existe experiência que não possa provocar transformações/aprendizagens, ficando implícita a ideia de movimento ininterrupto no processo de viver e de aprender.

Apresentamos a seguir, os depoimentos de alguns alunos acerca do que sentiram, perceberam, aprenderam, gostaram (ou não) de fazer durante a experiência vivida no Nicho de Aprendizagem Matemática:

O que eu mais gostei foi fazer a planta baixa porque é um negócio (sic), assim, que tu aprende fazendo, tu aprende muito! O que eu não gostei foi na hora de fazer os cálculos para a maquete, que daí deu muita enrolação (sic). Eu e a M. era um pouco individual, um estava fazendo isso e o outro aquilo; nós não compartilhávamos, ficava fechado (sic). Eu aprendi tudo sobre área,

13 O conceito de autopoiese ocupa um lugar privilegiado na teoria da Biologia do Conhecer, sendo, por vezes, utilizado como seu sinônimo. Consiste numa "palavra que procede de dois vocábulos gregos: auto - por si - e poieses - produção, simbolizando a ideia de autoprodução dos seres vivos" (PELLANDA, 2009, p.23). 
perímetro, sobre a maquete, sobre o jogo mesmo, conhecendo. Eu não fiz mais aquela coisa que fazia antes, que era botar os blocos do jeito que eu queria. Eu calculei quanto eu precisava, olhei onde eu queria fazer efetivamente a coisa e fui calculando enquanto que eu ia fazendo. Agora eu faço as coisas com um olhar diferente, com um olhar mais matemático (Le).

Antes (do projeto) eu tinha curiosidade de saber fazer e eu só pensava na minha casa, olhando de cima, e só desenhava os cômodos sem medida, sem ter nenhuma noção de tamanho, e agora eu já tenho uma noção maior. Eu achei legal, também, que a gente teve um momento mais junto, e não só a teoria, de aprender o conteúdo, fazer a prova e próximo conteúdo; a gente teve um tempo mais junto, convivendo entre professora e alunos. Eu acho que a gente fazendo essas aulas mais diferenciadas, digamos assim, a gente aprende mais; o que era explicado nas aulas, claro eu entendia um pouco, mas eu acho que eu entendi bem mais quando a gente fez na prática mesmo; quando a professora e o grupo estão juntos, conversando, facilita a aprendizagem. Com relação à matemática agora eu sei que não é só aquilo que está sendo explicado ali, eu posso explorar muito além; não é só fazer a conta e acabou, tem muito mais que eu posso explorar, muito mais coisas que podem envolver aquele conteúdo que a gente tem na sala $(\mathrm{N})$.

Eu gostei do novo estilo de aula que a gente teve. Gostei de fazer mais os cálculos mentais; por escrito eu não gosto porque eu tenho muita dificuldade de expressar o que eu estou pensando, o que eu estou sentindo que está tentando aparecer na minha cabeça eu não consigo te dizer, eu não consigo escrever, entende? Eu tenho dificuldade em escrever da forma como a professora pede que seja escrito. Depois do projeto eu comecei a fazer cálculos mais rápidos, comecei a ter entusiasmo; vi que tinha matemática não só naquilo, mas nisso, coisas diferentes, modos diferentes de ver a matemática. Com relação ao Minecraft, agora eu comecei a pensar mais no que eu estou fazendo quando jogo, mas não só no Minecraft, em outras coisas, em outros jogos também. Eu aprendi muito! (M).

Eu entendi que para aprender matemática não é só fazer essas contas de mais, menos, vezes e dividir; dá para fazer coisas diferentes e aprender $(\mathrm{J})$.

Tendo em vista as declarações explicitadas acima, depreendemos que, quando os processos de ensinar e aprender estão apoiados em dinâmicas que favorecem a cocriação pedagógica (professora e alunos criando juntos as dinâmicas de aprendizagem), a conversação (conversar com emoção), a convivência legítima (estar com o outro com respeito e aceitação) e a escuta atenta (abrir-se para ouvir o outro sem julgamento ou pré-conceitos), a aprendizagem acontece naturalmente, torna-se prazerosa e adquire sentido/propósito.

Também fica mais fácil para o(a) professor(a) e o aluno se assumirem como parceiros de aprendizagem, isto é, indivíduos compartilhando ideias, experimentando diferentes formas de 
ser e de entender os conteúdos desenvolvidos em sala de aula, aprendendo sobre si e sobre a matemática, transformando e sendo transformados por meio da convivência. Dessa forma, as relações educativas passam a se constituir na horizontalidade, ninguém melhor, nem pior, apenas diferente, numa comunhão de saberes e emoções que oportuniza, a cada um e a todos, ver/sentir/expressar o mundo de uma forma plural.

\section{Pistas que emergiram dessa experiência de convivência}

Diante do que surgiu da convivência no Nicho de Aprendizagem Matemática, apresentamos algumas pistas/possibilidades que entendemos ter potencial para serem precursoras do processo de aprendizagem da matemática:

- Desejo de aprender junto: os processos de ensinar e aprender matemática manifestam-se mais facilmente quando professor(a) e alunos têm a oportunidade de estar em acoplamento; isto é, convivendo e conversando, em legitimidade, sobre o que pensam e/ou percebem da matemática, visto que, conforme a Biologia do Conhecer, a aprendizagem está diretamente vinculada ao percurso da autoprodução do ser (autopoiese), que sempre ocorre em congruência com o meio.

- Ver sentido no que está sendo estudado: para favorecer a aprendizagem matemática as atividades devem ter sentido, ter "eco" dentro do aluno, perturbando-o a ponto dele querer aprender, pois a aprendizagem depende da complexificação da sua dinâmica interna (estrutura), ou seja, do quanto ele permite se transformar.

- $\quad$ Favorecer espaços de cocriação: as dinâmicas educativas são fruto de um conjunto de ações que vão sendo redimensionadas e acopladas ao espaço escolar por meio da convivência. Sendo assim, é importante que professor(a) e alunos possam se assumir como parceiros de aprendizagem, permitindo-se vivenciar situações pedagógicas que propiciem, a ambos, sentirem-se cocriadores dos processos de ensinar e aprender matemática.

- Oportunizar a conversação e a escuta atenta: aprender matemática implica em conversar sobre ela, perceber as relações que se estabelecem entre os números e o mundo, trocar ideias a respeito de como os conceitos matemáticos são percebidos e entendidos. Nesse sentido, a realização das atividades matemáticas deve ser permeada por conversas reflexivas e 
por movimentos recursivos de coordenações de coordenações de ações (MATURANA et al., 2009), dando ênfase ao processo vivido e refletido, e não, apenas, ao resultado obtido.

- $\quad$ Saber compreender e utilizar a linguagem matemática: o desenvolvimento do raciocínio matemático está intimamente relacionado à faculdade de saber comunicar uma ideia ou pensamento. Assim sendo, é importante que o aluno conheça e compreenda os símbolos matemáticos, objetivando utilizá-los com coerência na resolução de situações-problema, tanto na escola como na vida cotidiana.

- Utilizar os recursos tecnológicos, considerando as ideias da transposição informática: os softwares educativos têm o potencial de promover a ampliação do pensamento matemático quando utilizados como instrumento de mediação pedagógica, pois, dessa forma, viabilizam ao aluno experimentar algumas propriedades dos objetos matemáticos de maneira dinâmica, interativa e diferenciada.

\section{Algumas considerações finais}

Tendo em vista que o foco desta pesquisa era o mapeamento e a compreensão do que poderia acontecer num cenário de aprendizagem que ia surgindo no fluir do conviver entre uma professora de matemática e seus alunos, pontuamos que não há uma única proposta educativa ou metodológica que possa ser preestabelecida no intuito de desencadear a aprendizagem dos conceitos matemáticos. Existem, sim, diferentes maneiras de ver/perceber os processos educativos, e todas são legítimas, porque se originam das dinâmicas que emergem na e da convivência.

O Nicho de Aprendizagem Matemática foi um cenário educativo criado por esse grupo, visando a favorecer os processos de ensinar e aprender matemática de forma conjunta a partir da exploração do Minecraft. Consistiu numa experiência educativa pautada no conceito de convivência, à luz da teoria da Biologia do Conhecer, que foi emergindo num fluir de interações recursivas e em movimentos de coordenações de coordenações de ações (MATURANA et al., 2009) alicerçados na conversação (conversar com emoção), na escuta atenta, no respeito e aceitação de diferentes ideias, na suspensão de julgamentos e na parceria pedagógica.

Sendo assim, inferimos que essa experiência de convivência rompeu com os moldes

Periódico Horizontes - USF - Itatiba, SP - Brasil - e020053 
convencionais do ensino da matemática, na medida em que se originou da cocriação de atividades que tiveram potencial para desencadear aprendizagens matemáticas em convivência. Também enfatizamos a importância do acoplamento com o objeto matemático e com as possibilidades advindas do recurso digital (Minecraft), uma vez que a aprendizagem foi surgindo dos diálogos reflexivos possibilitados pelo jogo, em consonância com os saberes matemáticos que emergiam do grupo.

O convite que deixamos ao finalizar essas reflexões é que haja predisposição e abertura, tanto por parte do(a) professor(a) quanto dos alunos, em vivenciar experiências que sejam potencializadoras do aprender. Em outras palavras, que ambos possam se assumir como parceiros de aprendizagem, associando o "respeito e aceitação do outro como legítimo outro em convivência" (MATURANA, 2002, p.68) à cocriação pedagógica, favorecendo, assim, o surgimento de um cenário educativo onde seja possível encontrar sentido e ter prazer na aprendizagem matemática.

\section{Referências}

BALACHEFF, N. Entornos informaticos para la enseñanza de las matemáticas: complejidad didactica y expectativas. 2000. Disponível em:

http://www.cvrecursosdidacticos.com/download_file.php?file=1288115856_U2_Balacheff.pdf. Acesso em: 24 maio 2016.

COSTA, L. B. Cartografia: uma outra forma de pesquisar. Revista Digital do LAV, Santa Maria, v.7, n.2, p.66-77, maio/ago. 2014. Disponível em:

https://periodicos.ufsm.br/revislav/article/view/15111. Acesso em: 19 set. 2017.

DEVLIN, K. J. O gene da matemática. Trad. Sérgio M. Rego. Rio de Janeiro: Record, 2004.

DINIZ, M. I. Resolução de problemas e comunicação. In: SMOLE, K. S.; DINIZ, M. I. (orgs.). Ler, escrever e resolver problemas: habilidades básicas para aprender matemática. Porto Alegre: Artmed, 2001. p.87-97

FERNANDES, G. W. R. Práticas pedagógicas mediatizadas: delineando caminhos para a formação de professores de física na modalidade à distância. 2007. 280f. Dissertação (Mestrado em Educação Científica e Tecnológica) - Universidade Federal de Santa Catarina. Florianópolis, 2007. Disponível em: https://repositorio.ufsc.br/bitstream/handle/123456789/90430/245684.pdf?sequence=1\&isAll owed=y. Acesso em: 06 mar. 2017. 
ITZCOVICH, H. Iniciação ao estudo didático da geometria: das construções às demonstrações. São Paulo: Anglo, 2012.

MATURANA, H. R. Uma nova concepção de aprendizagem. Dois pontos, v.2, n.15, p.28-35, 1993. Disponível em: http://www.ead-

tec.furg.br/images/textos/uma_nova_concepcao_aprendizagem.pdf. Acesso em: 06 jun.2017.

MATURANA, H. R. Ontologia da realidade. Trad. e org. Cristina Magro, Miriam Graciano e Nelson Vaz. Belo Horizonte: Ed. UFMG, 2001a.

MATURANA, H. R. Cognição, ciência e vida cotidiana. Trad. e org. Cristina Magro, Victor Paredes. Belo Horizonte: Ed. UFMG, 2001b.

MATURANA, H. R. Emoções e linguagem na educação e na política. Trad. José Fernando C. Fortes. Belo Horizonte: Ed. UFMG, 2002.

MATURANA, H. et al. Matriz ética do habitar humano. 2009. Disponível em: http://escoladeredes.net/group/bibliotecahumbertomaturana. Acesso em: 09 maio 2017.

MATURANA, H. R.; DÁVILA, X. Y. El arbol del vivir. Santiago: MVP Editores, 2015.

MATURANA, H. R.; REZEPKA, S. N. Formação humana e capacitação. Trad. Jaime A. Clasen. Petrópolis: Vozes, 2000.

MATURANA, H. R.; VARELA, F. J. G. De máquinas e seres vivos: autopoiese - a organização do vivo. Trad. Juan A. Llorens. Porto Alegre: Artes Médicas, 1997.

MURTA, C. A. R.; VALADARES, M. G. P. F.; MORAES FILHO, W. B. Possibilidades pedagógicas do Minecraft: incorporando jogos comerciais na educação. In: EVIDOSOL, 12, CILTEC-online, junho/ 2015. Anais [...]., n.1, p.1-6. Disponível em: http://evidosol.textolivre.org. Acesso em: 26 dez. 2017.

PELLANDA, N.M. C. Maturana \& a educação. Belo Horizonte: Autêntica, 2009. [Coleção Pensadores \& Educação].

PONTE, J. P.; BROCARDO, J.; OLIVEIRA, H. Investigações matemáticas na sala de aula. Belo Horizonte: Autêntica, 2006.

SOARES, E. M. S.; RECH, J. Refletindo sobre processos educativos em ambientes virtuais à luz da Biologia do Conhecer. Informática na Educação: Teoria \& Prática. Porto Alegre, v.12, n.2, p.147155, jul./dez. 2009. Disponível em: http://seer.ufrgs.br/index.php/InfEducTeoriaPratica/article/view/9347/7256. Acesso em: 11 jul. 2017. 
VASCONCELLOS, M. J. E. Pensamento sistêmico: uma epistemologia científica para uma ciência novo-paradigmática. In: CONGRESSO BRASILEIRO DE SISTEMAS: despertando a consciência para a visão sistêmica: perspectivas para o século XXI, 1., 2005, Ribeirão Preto. Anais [...]. Ribeirão Preto: FEARP/USP, International Society for the Systems Sciences - ISSS, 2005. p.1-8. Disponível em: http://legacy.unifacef.com.br/quartocbs/arquivos/14.pdf. Acesso em: 08 mai. 2017.

Recebido em março 2020.

Aprovado em julho 2020. 